\title{
Outcome for patients colonised with Burkholderia cepacia in a Birmingham adult cystic fibrosis clinic and the end of an epidemic
}

\author{
K Muhdi, F P Edenborough, L Gumery, S O'Hickey, E G Smith, D L Smith, \\ D E Stableforth
}

Department of Medicine, Hexham General Hospital, Hexham, Northumberland NE46 10J, UK K Muhdi

Department of Adult CF Medicine F P Edenborough

Department of Physiotherapy L Gumery

Department of Microbiology E G Smith

Department of Respiratory Medicine D E Stableforth

Birmingham Heartlands Hospital, Bordesley Green East, Birmingham B9 5SS, UK

Department of Respiratory Medicine, Solihull Hospital, Solihull B91 2JL, UK S O'Hickey

Department of Respiratory Medicine, Glenfield General Hospital, Leicester LE3 9QE, UK D L Smith

Correspondence to: Dr D E Stableforth

Received 19 June 1995 Returned to authors 29 September 1995 Revised version received 21 November 1995 Accepted for publication 23 November 1995

\begin{abstract}
Background - There has been increasing concern since 1979 about the emergence of Pseudomonas cepacia (Burkholderia cepacia) in patients with cystic fibrosis in the UK and elsewhere. Colonisation of the sputum has been shown to be associated with increased morbidity and mortality. Evidence suggests person to person transmission and some centres have segregated those colonised with $B$ cepacia from other patients with cystic fibrosis. The outcome of patients colonised by $B$ cepacia has been studied, together with the effects of strict segregation.
\end{abstract}

Methods - The outcome in 18 patients with sputum colonised by $B$ cepacia was compared with that in age, sex, and severity matched controls with no evidence of $B$ cepacia colonisation by a retrospective case note study.

Results - No differences between cases or controls were found in the 24 month period prior to colonisation by $B$ cepacia in lung function, number of days in hospital, or outpatient visits. Colonisation led to an increased rate of loss of lung function and utilisation of hospital services. There was an increase in the numbers of transplants and deaths amongst the cases. Since 1992 there have been only three new cases of $B$ cepacia colonisation and the incidence and prevalence of the organism has fallen dramatically since segregation commenced. Conclusions - B cepacia appears to be linked to the decline in colonised individuals. There was no evidence that colonisation occurred in patients declining for other reasons. $B$ cepacia colonisation confers a worse prognosis than Pseudomonas aeruginosa alone. Segregation appears to limit the spread of the organism from infected individuals to other patients with cystic fibrosis.

(Thorax 1996;51:374-377)

Keywords: cystic fibrosis, Pseudomonas cepacia, outcome

Patients with cystic fibrosis usually become colonised with Pseudomonas aeruginosa as they get older; however, a newer organism has recently given cause for concern. Burkholderia cepacia (previously Pseudomonas cepacia) is a ubiquitous environmental pathogen that causes a variety of infections in patients with diminished defences. ${ }^{1}$ Colonisation of the respiratory tract with $B$ cepacia in patients with cystic fibrosis has been recognised since $1979,{ }^{2}$ and has been associated with significant morbidity and mortality with up to one third of patients dying within six months and a further third experiencing a significant loss of lung function. ${ }^{34}$

The first report of isolation of $B$ cepacia in the United Kingdom from a patient with cystic fibrosis who subsequently died was in $1986 .{ }^{5}$ Whilst infection may occur de novo in some patients, there is increasing evidence of person to person transmission ${ }^{5-8}$ - for example, by inhalation of contaminated aerosol droplets ${ }^{9}$ or direct contact through hand shaking. ${ }^{1 n}$ It is generally accepted that acquisition of $B$ cepacia should be avoided ${ }^{11-13}$ and the French Cystic Fibrosis Association (AFLM) has declared, in a multinational consensus, that "the cystic fibrosis patient infected with Pseudomonas cepacia is currently the major source of Pseudomonas cepacia for other cystic fibrosis patients". ${ }^{14}$ For these reasons patients colonised with $B$ cepacia have been segregated by our unit since 1988 by provision of separate wards and outpatient clinics.

We have compared our experience of patients colonised with $B$ cepacia with matched controls in whom $B$ cepacia has not been isolated, and have attempted to ascertain whether acquisition is incidental to an increased rate of decline due to other factors or whether colonisation itself leads to the observed decline. We further report the end of an epidemic of new cases by a policy of both in-hospital and social segregation.

\section{Methods}

The population comprised 167 patients who had ever attended the Adult Cystic Fibrosis Unit at Birmingham Heartlands Hospital between 1989 and 1993 whose outcome was known. The cases included 18 patients from whom $B$ cepacia was isolated from one or more sputum samples and identified from the time of the first isolation of the organism (the "colonisation date"). Data were collected for 24 months before this and six months thereafter. Insufficient data were available on two cases and 16 were studied. Sixteen patients from whom $B$ cepacia had never been isolated were identified and matched for age, sex, and within $10 \%$ of the forced vital capacity (FVC $\pm 10 \%)$ at the beginning of the study, 24 months before 
Table 1 Mean (range) of data in cases colonised with $B$ cepacia (nine men) and $B$ cepacia negative controls

\begin{tabular}{|c|c|c|c|}
\hline & Colonised patients & Controls & $p$ value \\
\hline Age & $25 \cdot 5(21-33)$ & $26 \cdot 5(19-36)$ & NS \\
\hline$\% \mathrm{FEV}_{1}$ & $41 \cdot 4(21-98)$ & $49 \cdot 9(23-78)$ & NS \\
\hline$\% \mathrm{FVC}$ & $69(29-116)$ & $60 \cdot 6(31-119)$ & NS \\
\hline$\% \mathrm{IBW}$ & $81(54-98)$ & $90(72-104)$ & $<0.05$ \\
\hline \multicolumn{4}{|l|}{ Genotype } \\
\hline $\mathrm{dF} 508 / \mathrm{dF} 508$ & $9 / 14$ & $10 / 15$ & \\
\hline dF508/other & $3 / 14$ & $4 / 15$ & \\
\hline Unavailable & $2 / 14$ & $1 / 15$ & \\
\hline \multicolumn{4}{|l|}{ Microbiology } \\
\hline P aeruginosa alone & $8 / 15$ & $12 / 15$ & \\
\hline$P$ aeruginosa + Staph aureus & $5 / 15$ & $2 / 15$ & \\
\hline Staph aureus alone & $1 / 15$ & - & \\
\hline
\end{tabular}

$\mathrm{FEV}_{1}=$ forced expiratory volume in one second; $\mathrm{FVC}=$ forced vital capacity; IBW = ideal body weight.

Table 2 Mean (SD) rates of decline in lung function and body weight before and after colonisation

\begin{tabular}{|c|c|c|c|}
\hline & Colonised patients & Controls & $p$ value \\
\hline \multicolumn{4}{|c|}{$\mathrm{FEV}_{1}(\mathrm{ml} /$ month$)$} \\
\hline Before & $-6 \cdot 8(20)$ & $-8.99(16 \cdot 1)$ & NS \\
\hline After & $-29 \cdot 2(56)$ & $+7 \cdot 0(28 \cdot 6)$ & $<0.05$ \\
\hline \multirow{2}{*}{\multicolumn{4}{|c|}{ FVC (ml/month) }} \\
\hline & & & \\
\hline Before & $-5 \cdot 5(29)$ & $-3 \cdot 6(24 \cdot 6)$ & NS \\
\hline After & $-41 \cdot 4(66)$ & $+16 \cdot 5(46 \cdot 2)$ & $<0.02$ \\
\hline $\mathrm{p}$ value & $<0.05$ & NS & \\
\hline \multicolumn{4}{|c|}{ Weight $(\mathrm{kg} /$ month) } \\
\hline Before & $+0.079(0.215)$ & $+0.082(0.204)$ & NS \\
\hline After & $-0.072(0.655)$ & $-0.009(0.267)$ & NS \\
\hline $\mathrm{p}$ value & NS & NS & \\
\hline
\end{tabular}

$\mathrm{FEV}_{1}=$ forced expiratory volume in one second; $\mathrm{FVC}=$ forced vital capacity.

Table 3 Mean (SD) outpatient attendance and inpatient days before and after colonisation

\begin{tabular}{|c|c|c|c|}
\hline & Colonised patients & Controls & $p$ value \\
\hline \multicolumn{4}{|c|}{ Outpatient visits per 6 months } \\
\hline Before & $3 \cdot 2(1.5)$ & $2 \cdot 8(1 \cdot 26)$ & NS \\
\hline After & $4.7(1.8)$ & $3.5(1.76)$ & NS \\
\hline $\mathrm{p}$ value & $<0.01$ & NS & \\
\hline \multicolumn{4}{|c|}{$\begin{array}{l}\text { Hospital inpatient days per } 6 \\
\text { months }\end{array}$} \\
\hline Before & $9 \cdot 7(10)$ & $11 \cdot 7(19 \cdot 6)$ & NS \\
\hline After & $36 \cdot 3(17)$ & $11.8(14.5)$ & $<0.001$ \\
\hline $\mathrm{p}$ value & $<0.001$ & NS & \\
\hline
\end{tabular}

the "colonisation date" of their respective controls.

$B$ cepacia strains were isolated with a standard selective medium used since 1989 and identified by techniques described elsewhere. ${ }^{15}$ Isolates identified in our laboratory were confirmed by the Central Public Health Laboratory, Colindale, London, UK. Details of the microbiological methods including ribotyping and pulsed gel electrophoresis by the clamped homogenous electric field (CHEF) technique, which included the typing of 17 of the 18 patients, have been described previously. ${ }^{8}$

\section{OUTCOME MEASURES}

At each hospital attendance the forced expiratory volume in one second $\left(\mathrm{FEV}_{1}\right)$, forced vital capacity (FVC), and body weight were routinely measured and recorded in the notes. Results were expressed as percentage predicted lung function $\left(\% \mathrm{FEV}_{1}, \% \mathrm{FVC}\right)^{16}$ and percentage ideal body weight (\%IBW) ${ }^{17}$ Rates of change were expressed as $\mathrm{ml} / \mathrm{month}$ and $\mathrm{kg}$ / month for lung function and weight, respectively. The number of outpatient visits over the 30 month period was expressed as attendances per six months and the number of hospital inpatient days for treatment of pulmonary exacerbations was expressed as the number of days per six months. The dates of transplantation or death were noted.

\section{STATISTICAL ANALYSIS}

The clinical data were considered to be normally distributed and were analysed between groups with the Student's $t$ test and before and after colonisation with the paired $t$ test. Variations between the group trends were analysed with interaction plots. Comparison of proportional outcomes was with the $\chi^{2}$ test (Yates' correction).

\section{Results}

MATCHING OF CASES AND CONTROLS

There were 16 patients (nine men) in each group with similar cystic fibrosis genotypes and sputum microbiology (table 1). No significant differences were found between the two groups in age, lung function $\left(\% \mathrm{FEV}_{1}, \% \mathrm{FVC}\right)$ or body weight (table 2), nor were there any differences in the rate of decline of $\mathrm{FEV}_{1}, \mathrm{FVC}$, or body weight, or the number of outpatient visits or inpatient days per six months in the two years prior to the colonisation date (table 3 ).

\section{CHANGES AFTER COLONISATION}

Lung function (table 2)

After the colonisation date both $\mathrm{FEV}_{1}(\mathrm{p}<0.05)$ and FVC $(\mathrm{p}=\mathrm{NS})$ were increased in the control group while in the $B$ cepacia group lung function was reduced (FVC, $\mathrm{p}<0.05 ; \mathrm{FEV}_{1}, \mathrm{p}=\mathrm{NS}$ ). Since case numbers were small with large variability in lung function both within and between patients, standard deviations were large and significant trends may have been masked. Analysis of variance between pairs within the groups over the whole study to produce an interaction plot revealed significant differences in the trends with loss of both FVC $(\mathrm{p}<0.01)$ and FEV $_{1}(\mathrm{p}=0.02)$ in the $B$ cepacia group compared with small increases in lung function in the controls.

\section{Body weight (table 2)}

Despite attempted matching, the control group was significantly heavier than the $B$ cepacia group. Both groups gained weight before the colonisation date and began to lose it thereafter. Although the $B$ cepacia group gained less and went on to lose weight more rapidly, no significant difference in the rates or trends were revealed by the interaction plot, both groups showing a small loss over the study.

Outpatient attendances and inpatient days (table 3)

Following the colonisation date the number of outpatient visits rose in both groups, but significantly so only in the $B$ cepacia group $(p<0.01)$. The number of inpatient days rose sharply in the $B$ cepacia group ( $p<0.001)$, with no change in the control group. 
Table 4 Outcome following colonisation as at December 1994 (survival in months)

\begin{tabular}{|c|c|c|c|c|c|c|}
\hline & \multicolumn{3}{|c|}{ Colonised patients } & \multicolumn{3}{|l|}{ Controls } \\
\hline & No. & $\%$ & Mean (range) & No. & $\%$ & Mean (range) \\
\hline All patients & $18^{*}$ & & & 16 & & \\
\hline Alive & 7 & $39 \%$ & $56(35-91)$ & 11 & $69 \%$ & $42(12-89)$ \\
\hline Dead & $11^{*}$ & $61 \%$ & $10(1-33)$ & 5 & $31 \%$ & $33(-5-76)$ \\
\hline Transplanted & $7 \dagger(4$ died $)$ & $39 \%$ & $22(1-40)$ & 2 (1 died) & $12 \%$ & $26(22-30)$ \\
\hline
\end{tabular}

* Including two patients on whom serial data were incomplete.

† One patient with incomplete data was transplanted and died after two weeks.

Outcomes (table 4)

Of the 18 patients colonised with $B$ cepacia, seven have been transplanted at a mean of 22 (range 0.5-40) months after colonisation. Three died within a month of surgery due to $B$ cepacia septicaemia, three remain alive at 59 (41-87) months after transplantation, and the seventh died after eight months from an unrelated cause. Of the 11 not transplanted, four are alive at $37(35-39)$ months and seven died at 13 (2-33) months, all from overwhelming $B$ cepacia infection. Two patients succumbed whilst on full ventilation awaiting transplantation. Of the controls, two have been transplanted at 22 and 30 months. One died at 13 months, the other is alive at 12 months. Ten patients are alive at 44 (29-89) months without transplantation and four have died 33 (-5-76) months after colonisation.

Due to the small numbers involved, a comparison of the proportions of deaths and transplanted patients between groups was not statistically significant; however, $61 \%$ of patients colonised with $B$ cepacia have died compared with $31 \%$ of controls and $39 \%$ of colonised patients have required transplantation compared with $12.5 \%$ of controls.

Since the end of the study three further patients have been identified as having $B \mathrm{ce}$ pacia, the last in January 1994; none have been transplanted, two are alive at eight and 21 months after colonisation, but one who had been in the control group acquired $B$ cepacia and died within five months of colonisation.

\section{Discussion}

The impact of $B$ cepacia colonisation on patients with cystic fibrosis has been similar in Canada, ${ }^{6}$ the USA, ${ }^{18}$ and the $\mathrm{UK}^{8}$ and has already been described. The policy of segregation has been reported for $P$ aeruginosa and is believed to have limited the spread of an epidemic multiresistant strain in one clinic. ${ }^{19}$ Segregation of patients colonised with $B$ cepacia has been advocated since $1986 .^{20}$

In 1987 one of 52 patients in our adult cystic fibrosis clinic became colonised. In total 21 of 192 patients were affected up to December 1994. In-hospital segregation was initiated in 1988 but increasing incidence led to the recommendation of social segregation in 1991. Thereafter the incidence fell and a peak prevalence of 12 live patients among $143(8.4 \%)$ was reached in 1993; numbers have since fallen to six in 152 following loss through death or transplantation.

Our experience shows that, of 21 patients, five died and two were transplanted within six months. Three died between 18 months and three years and five were transplanted in the same period. Of the seven transplanted patients three died of overwhelming $B$ cepacia septicaemia within a month of surgery, in keeping with experience elsewhere of mortality rates up to $50 \%$ within the first postoperative month. ${ }^{21}$ Six remain reasonably well over periods of five months to three years following colonisation.

Why $B$ cepacia colonisation should apparently cause profound deterioration in some patients whilst others remain clinically unaffected has not been explained, hence the suggestion that $B$ cepacia colonisation follows deterioration due to other causes. Having matched cases and controls as closely as possible and allowing for the slight difference in body weight, our experience suggests that those patients who go on to develop $B$ cepacia colonisation are no different from controls with respect to age, sex, genotype, microbiology, or severity measured directly by lung function, or indirectly by assessing inpatient days or outpatient visits.

Within the 24 months prior to colonisation there was no evidence of early deterioration since the rates of change in lung function, weight, outpatient visits, and inpatient days were similar in each group. Separate analysis of each six month period also failed to show any difference in absolute values or trends for $\mathrm{FEV}_{1}$, FVC, body weight, or outpatient visits prior to the colonisation date.

It is of interest that the mean $\% \mathrm{FEV}_{1}$ and $\% \mathrm{FVC}$ of the control group improved over the period of study in seven of the 16 patients; this may be accounted for by an improvement in the lung function in patients who have recently arrived in the adult clinic after institution of optimum respiratory care. This improvement is not seen in all patients and is eventually followed by the expected gradual decline.

The small rise in the number of inpatient days in the six months prior to colonisation in the $B$ cepacia group is unexplained. It is unlikely that the organism was acquired in hospital since segregation was instituted early. A possible explanation is seen in a report that $B$ cepacia identified at different clinics and ribotypically distinct from other local cases was cultured from two patients and found to be indistinguishable by ribotyping from an index case with whom they had had contact at a summer camp 12 and 24 months before their first positive cultures. ${ }^{22}$ This suggests the possibility of inapparent transmission of the organism which may remain undetected until months later.

Most patients harbour individual "wild" strains of $B$ cepacia; however, ribotyping techniques have identified strains in a number of UK centres which are indistinguishable, thus suggesting passage between clinics. This "epidemic" strain may be more transmissable and perhaps more virulent than the "wild" strains (T Pitt, Central Public Health Laboratory, personal communication). We compared 10 patients colonised with the "epidemic" strain and four with "wild" strains (four not available for ribotyping ${ }^{8}$ ). Seven of the 10 with the "epi- 
demic" strain died as did three of the four with the "wild" strains. Four patients with the "epidemic" strain were transplanted; three died within a month, the fourth some months later due to an unrelated cause. None of the "wild" strains required transplantation.

Whilst it is not clear from our small number of patients whether there is an increased morbidity and mortality in those with the "epidemic" B cepacia strain, it is interesting to note that the three patients colonised and transplanted before the policy of segregation was instituted and before identification of the "epidemic" strain was possible have done remarkably well and are alive at $4 \cdot 2-8 \cdot 25$ years after transplantation. They acquired their $B$ cepacia a minimum of 18 months before the first isolation of the epidemic strain. The fourth patient acquired $B$ cepacia 11 months before the first epidemic isolate and died five months later.

No factors were found to account for the increased rate of decline in lung function or the increased reliance on inpatient and outpatient services by the cases other than that they had become colonised with $B$ cepacia. This study suggests that the increased morbidity and mortality after colonisation by $B$ cepacia are directly due to the acquisition of this organism rather than to the opportunistic colonisation of patients who are already in decline.

Since transmission of $B$ cepacia appears to occur from person to person, we believe our policy of in-hospital and recommended social segregation to be necessary to limit the spread, even though this has been difficult for patients, relatives, and staff. We are fortunate to have passed the peak of the epidemic but believe that we must continue to provide separate facilities at our centre and to give sympathetic advice and support when problems arise.

1 Goldmann DA, Klinger JD. Pseudomonas cepacia: biology, mechanisms of virulence and epidemiology. F Pediatr 1986 108:806-12.
2 Blessing J, Walker J, Maybury B, Yeager AS, Lewiston N. Pseudomonas cepacia and maltophilia in the cystic fibrosis patient. Am Rev Respir Dis 1979;119:262.

3 Isles A, Maclusky I, Corey M, Gold R, Prober C, Fleming P, Levison H. Pseudomonas cepacia from cystic fibrosis: an emerging problem. F Paediatr 1984;104:206-10.

4 Thomassen MJ, Demko CA, Klinger JD, Stern RC. Pseudomonas cepacia colonisation amongst patients with cystic fibrosis. A new opportunist. Am Rev Respir Dis 1985;131: 791-6.

5 Glass S, Govan JRW. Pseudomonas cepacia - fatal pulmonary infection in a patient with cystic fibrosis. F Infect 1986;13: 157-8.

6 Millar-Jones L, Paull A, Saunders Z, Goodchild MC. Transmission of Pseudomonas cepacia in patients with cystic mission of Pseudomonas cepacia

7 Nelson JW, Doherty CJ, Brown PH, Greening AP, Kaufmann ME, Govan JRW. Pseudomonas cepacia in patients mann ME, Govan JRW. Pseudomonas cepacia
with cystic fibrosis. Lancet 1991;338:1525.

8 Smith DL, Gumery LB, Smith EG, Stableforth DE, Kaufmann ME, Pitt TL. Epidemic of Pseudomonas cepacia in an adult cystic fibrosis unit: evidence of person-to-person transmission. $\mathcal{f}$ Clin Microbiol 1993;31:3017-22.

9 Humphreys H, Peckham D, Patel P, Knox AJ. Airborne dissemination of Burkholderia (Pseudomonas) cepacia from adults with cystic fibrosis. Thorax 1994;49:1157-9.

10 Pegues DA, Carson LA, Tablan OC, Fitzsimmons SC, Roman JB, Miller JM, et al and the Summer Camp Study Group. Acquisition of Pseudomonas cepacia at summer camps for patients with cystic fibrosis. MMWR 1993;42: camps for

11 Editorial. Pseudomonas cepacia - more than a harmless commensal? Lancet 1992;339:1385-6.

12 Prince A. Pseudomonas cepacia in cystic fibrosis patients. An Rev Respir Dis 1986;134:644-5.

13 Editorial. Stableforth DE, Smith DL. Pseudomonas cepacia in cystic fibrosis. Thorax 1994;49:629-30.

14 Doring G, Schaffer L, eds. Epidemiology of pulmonary infection by Pseudomonas in patients with cystic fibrosis: a consensus report. Paris: AFLM, 1993:4.

15 Gilligan PH, Gage PA, Bradshow LM, Schidlow DV, DeCicco BT. Isolation medium for the recovery of Pseudomonas cepacia from the respiratory secretions of patients with cystic fibrosis. $f$ Clin Microbiol 1985;22:5-8.

16 ECCS standardised lung function testing. Bull Eur Physiopathol Respir: Clin Respir Physiol 1983;19(Suppl 5):1-95.

pathol Respir: Clin Respir Physiol 1983;19(Suppl 5):1-95.
17 Jelliffe DB. The assessment of the mutritional status of the community. Geneva: World Health Organisation Monocommunity. Geneva: World
graph Series. No. 53, 1966.

18 Lewin LO, Byard PJ, Davis PB. Effect of Pseudomonas cepacia colonisation on survival and pulmonary function of cystic fibrosis patients. F Clin Epidemiol 1990;43:125-31.

19 Hoiby N, Pedersen SS. Estimated risk of cross infection with Pseudomonas aeruginosa in Danish cystic fibrosis patients. Acta Paediatr Scand 1989;78:395-404.

20 Thomassen MJ, Demko CA, Doershu CF, Stern RC, Klinger JD. Pseudomonas cepacia: decrease in colonisation in patients with cystic fibrosis. Am Rev Respir Dis 1986; 134:669-71.

21 Snell GI, de Hoyos A, Kradjden M, Winton T, Maurer Jr. Pseudomonas cepacia in lung transplant recipients with Pseudomonas cepacia in lung transplant
cystic fibrosis. Chest 1993;103:466-71.

22 Lipuma JJ, Marks-Austin KA, Holsclaw DS, Winnie GS Gilligan PH, Stull TL. Inapparent transmission of PseudoGilligan PH, Stull TL. Inapparent transmission of Pseudo-
monas (Burkholderia) cepacia among patients with cystic monas (Burkholderia) cepacia among patient
fibrosis. Pediatr Infect Dis f 1994;13:716-9. 